\title{
Channel Buoys in Ports for Navigation
}

\author{
Thenmozhi R ${ }^{\mathrm{a}, 1}$, Aarthi $\mathrm{N} \mathrm{R}^{\mathrm{b}}$, Bharkavi $\mathrm{P}^{\mathrm{b}}$, Asvitha R ${ }^{\mathrm{b}}$, Anne Esther $\mathrm{S}^{\mathrm{b}}$ \\ ${ }^{a}$ Assistant Professor,Dept of EIE, Panimalar Engineering College, Chennai \\ ${ }^{b} U . G$ Scholar, Dept of EIE, Panimalar Engineering College, Chennai
}

\begin{abstract}
Buoy is a device which floats in the sea water, used to direct the ships in which this paper is preferable to get electricity from salt water/ sea water by using two tongue depressor. Using level sensor has per this paper, where going to sense distance between a ship / a boat and a buoy, regarding the distance between those two objects, alarms or buzzers may indicates. An IOT applications has been implemented on a buoy, so that if any obstacles damage a buoy, the information can be specified to the communication station through SIM900
\end{abstract}

Keywords. Electricity drawn from salt water, IOT using SIM900, Level sensor IP68

\section{Introduction}

Buoy is a device which floats in sea level, helps to direct the marines and the ship sailors. This buoy indicates the sign of road in water. It is basically painted in bright colors. Buoy is mainly classified as red buoy and green buoy. In ports the ships and boats are called as vessels. The channel buoy helps to transmit the vessel in and out of ports by showing particular color lights. The total number of channel include 0-9 numbers where odd numbers $1,3,5,7,9$ are red channels whereas remaining even number $0,2,4,6,8$ are green channels. These channels are located mainly in the entrance of each and every port. The red light indicates the ship not to go that side because here the depth of seawater or depth of sea level is not sufficient for the ship to move. But the green light side, the respected harbor would have diged the sea ground level for the ships to enter. In green level side, the depth will be more when compared to the red light channel side. The reason why the buoy float is because they are made of materials which are of less dense than sea water. Or else this tank makes them dense than water. The channel is mainly is identified by its type of color, shape, information which has been printed on it. The red channel is shaped different from green channel. Here the top of the red channel is small when compared to bottom. When appears like inverted cone in green channel. It is a cylindrical shape. The shape of the channel buoy helps to identify the direction even in the case of no light glowing. The light on the channel may disappear due to fog and sometimes of visibility and electricity. Channels are strongly built in case of tidal storm surge. Even if they are affected, it will come back to the floating position. This channel is buoy's and merged only due to heavy storm and other transient water disaster. But small water disaster like tide and all, buoys won't merge.

\footnotetext{
${ }^{1}$ Thenmozhi R,Assistant Professor,Dept of EIE,Panimalar Engineering College, Chennai, Email: thenmozhi2689@gmail.com
} 


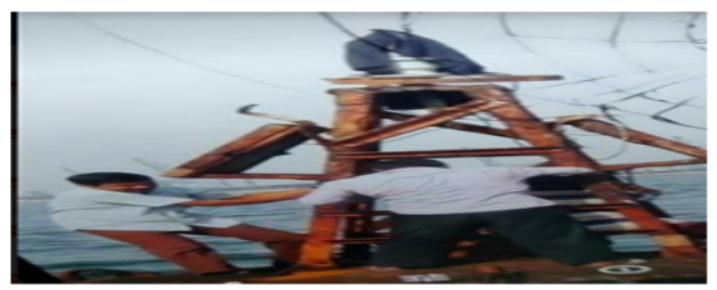

Figure1. Bouy

\section{Existing System}

Basically buoy has two parts, one part floats on the sea level but the other end totally merged or permanently merged under water. The upper part is held tightly in two end by the iron chains. These chains are perpendicularly to each other and joins together in the SEVAL block. And this gets finally attached with the gigantic iron ball of two tones, so that the buoy will be permanently placed in the same place. These types buoy's are used in countries like USA, German etc.... But in India Mooring and CAN buoy are only in existence. The existing system in India of buoy has a permanent LED pilot light and a 12 volt battery which can be replaced year by year. Replacing is the battery is done by man power which is so risky. There is a common problem in all ports that those buoy's has been and being damaged by ships which are entering and leaving ports.

\section{Proposed System}

\subsection{Block Diagram}

\subsubsection{Process-1}

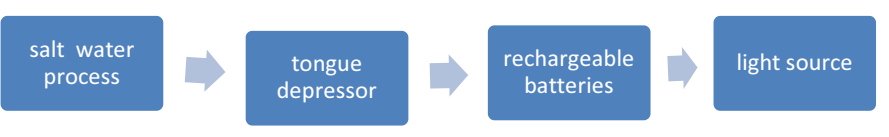

Figure 2. Salt water process

\subsubsection{Process -2}

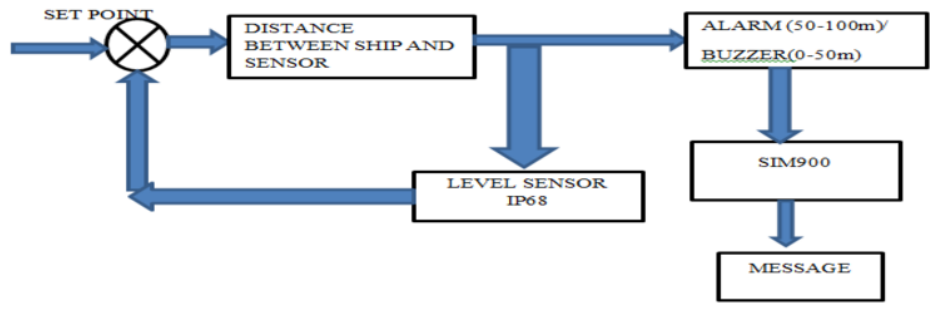

Figure 3. SIM900 and IP68 


\subsection{SIM900}

It is a quad band GPS solution which is in SMT module and this can even be embedded in customer application. SIM900 gives a voice notice, SMS and tax. It is performed in low power consumption. It has a configuration of $24 \mathrm{~mm} * 24 \mathrm{~mm} * 3 \mathrm{~mm}$., It is very tiny in design. SIM900 is a single chip processor which get integrated by AMR926EJ-S core. It is a type of embedded IP protocol stack.

Table 1. SIM900

\begin{tabular}{|l|l|}
\hline \multicolumn{1}{|c|}{ QUALITY TYPE } & \multicolumn{1}{|c|}{ SPECIFICATION } \\
\hline Quad-band & $850 / 900 / 1800 / 1900 \mathrm{MHz}$ \\
GPRS mobile station & Class B \\
Weight & $3.4 \mathrm{gram}$ \\
Dimensions & $24 \mathrm{~mm}^{*} 24 \mathrm{~mm}^{*} 3 \mathrm{~mm}$ \\
Voltage range & $3.4 \mathrm{v}-4.5 \mathrm{v}$ \\
Power consumption & $1.0 \mathrm{~mA}$ \\
& \\
\hline
\end{tabular}

\subsection{IP68 Level Sensor}

Here the number 6 has dust entering capacity protection. It indicates the capacity of sensor. For the permanent immerging in water. This IP68 can able to sense the elements or object6s which are in the distance up to 100meters. According to our journal, if the ship or boat reaches 50 to 100 meters from the IP68 which is placed in the channel buoy. The alarm starts to indicate the ship or boat even in the case if the ship reaches more closer (1to50m) the Ip68 makes the buzzer to indicate.

Table 2. P68

\begin{tabular}{|l|l|}
\hline \multicolumn{1}{|c|}{ QUALITY TYPE } & \multicolumn{1}{|c|}{ SPECIFICATION } \\
\hline Output & $4-20 \mathrm{~mA}, 0-10 \mathrm{~mA}, 0-5 \mathrm{~V}, 1-5 \mathrm{~V}$ \\
Accuracy & $0.2 \% \mathrm{Fs}$ to $0.5 \% \mathrm{Fs}$ \\
Power supply & $24 \mathrm{VDC}$ \\
Stability & $0.25 \% \mathrm{Fs}$ \\
Level Range & 0 to $200 \mathrm{~m} \mathrm{H} 2 \mathrm{O}$ \\
& \\
\hline
\end{tabular}

\subsection{Salt Water Process}

Salt water commonly consists of sodium and chlorine ions which is denoted as $\mathrm{Na}+$ cl-ions. Here $\mathrm{Na}+$ ions or sodium ions acts as anode and cl- ions as chlorine ions acts 
as cathode in the circuit. This full structure in the salt water is called as electrolyte. This anode and cathode together brings an electricity to the battery. The $\mathrm{pH}$ level of salt water is 7.5-8.4. In normal water 1.23 volts can be produced whereas in salt water 2.6 volts can be produced. This 2.6 volts is very much required to glow a LED bulb. Sea water contains 60 to 100 times more irons than in normal water. This sea water process makes it possible far more electricity than the amount used to charge the battery. This process is renewable and environmental friendly. Since the sea water is widely available, this process is of low cost. There is less dependence of oil gas.

\subsection{Rechargeable Batteries}

The rechargeable batteries are used in the buoys has per or journal. These rechargeable batteries are placed here in order to store the electricity from the sea water permanently. Norma batteries are been replaced by the rechargeable batteries to reduce the man power and time. These rechargeable batteries gets recharged from the sea water after all the electricity is drained automatically.

\subsection{Alarm}

The alarms using here is to indicate that the ship or boat may tend to touch or hit the channel buoy as per our journal the sensing element senses. The level up to $100 \mathrm{~m}$ from the buoy, when the boat or ships reaches 50 to $100 \mathrm{~m}$ the sensing element senses.

\subsection{Buzzer}

The buzzers using here to indicate the ship which is going to hit the buoy. This buzzer indicates when the ship reaches the distance 0-50 meters to the buoy. As per our journal ,the sensing elements IP68 senses the distances and gives information to the buzzer to indicate the ship which is nearer.

\section{Literature Survey}

Buoy which is international wise used has not been developed up to the modern date. If the buoy had replaced by the recharging batteries instead of replaceable batteries of constant $12 \mathrm{v}$, there is a reduce in man power and even of cost reduction. the replacing of batteries in buoy over at the middle of sea water is a risky job. So with the help of rechargeable batteries, this may be avoided. These batteries can be recharged by two tongue depressors which has been wrapped by the aluminum foil. One end of each depressors has been immerged in the sea water and the other end of the two depressor is connected to battery and bulb. therefore there may be a chance of getting electricity from the sea water to glow the bulb now the SIM900 has been used to communicate with the respected port about the present condition of channel buoy, this SIM900 is a GPRS configuration which gives information in the form message, call or fax etc...Dimension of SIM900 is $24 \mathrm{~mm} * 24 \mathrm{~mm} * 3 \mathrm{~mm}$.It is a SIM like structure and requires a voltage range of 3.4 volt to 4.5 volt. The IP68 is also been placed to sense. Ip68 is water level sensor which immersed in sea water to measure the distance between ship or boat and the buoy. It measure the distance of 100 meters by sensing it. 
When the ship nearer the distance of 50-100 meters, the IP68 senses and gives the information to the controller to sound the alarm. So that the ship may identify and rectify it. If the ship nearer 0-50meters, the IP68 senses and immediately gives the information to the controller, now to sound the buzzer.

\section{Result}

By using salt water to generate electricity is the very cheapest form. This electricity is as much required to the battery to glow a LED bulb, which has been placed in the top of channels buoys. By replacing the rechargeable batteries there is no need of man power which is so risky enough. The tongue depressor has been wrapped by the aluminum foil. One end of the 2 depressor is dipped or merged in sea water and the other two ends are connected with positive of battery and LED bulb.

By using IP68 sensor, it measures the distance between ship or boat and a channel buoy. This IP68 is actually a level measuring sensor immerged in the sea water of 1 meter. If this sensor has immerged above the distance of 1 meters in the sea level, it may not work or give the accurate measurement. This IP68 measures the distance of 100 meters perpendicular to the buoy. If the ship nearers50 to 100 meters to the buoy, this elements senses and gives information to the controller to sound the alarm in order to indicate the ship to change its direction. If this ship reaches more nearer of ranging 0-50 meter, this element senses and gets the same information to the controller ,now to sound the buzzer. By sensing all those the damage of buoy can be controlled majorly. At last by using SIM900 which is an IOT application, it can able to inform to the communication station, if there is a damage in the buoy. This SIM900 is used in the case when all other cases has been failed ie. if the ship nearer the buoy even after the indication of both alarm and buzzer.

\section{Future Scope}

If the current or existing buoy has been replaced by our above ideas, a modern buoy can be given to our ports in India. Those above ideas are of mostly cheap of cost which are eligible to prefer by our ports.

\section{References}

[1] Mainly by our vision and experience in harbor.

[2] Chapman's piloting and seamanship(58th edition)- Charles Frederic Chapman(This book has been called as BIBBLE OF BOATING.

[3] Sea water information- Tech engineering STEM curriculum for K-12.

[4] Electricity information by-science daily.com/releases/2019/07/190729151859.htm>

[5] SIM900 information by- Stanford(news science) march 28, 2011.

[6] A Hybrid Petri Net Approach for Polyethylene Terephthalate Bottle Manufacturing System B Muthuraj, V Mahesh, R Senthil - Journal of Computational and Theoretical Nanoscience, 2016.

[7] Simulation Of Three Tank System Using Hybrid Perti Net For Batch Process Dr. R.Senthil B.Muthuraj, Dr.V.Mahesh 2015/11/2 International Journal of Applied Engineering Research 4789-4798 Research India. 